\title{
Rehabilitación de un caso de afasia acústico-mnésica como resultado de un trauma craneoencefálico: un abordaje Luriano
}

\author{
Réhabilitation d'un patient atteint d'aphasie acoustique mnésique après un traumatisme crânien : une approche Lurienne \\ Reabilitação de um caso de afasia acústico-mnésica como resultado de um traumatismo cranioencefálico: uma abordagem Luriana
} Rehabilitation of a patient with acoustic-mnestic aphasia after brain trauma: a Lurian approach

\section{Jamile Chastinet ${ }^{1}$, Caio Morais ${ }^{1}$, Yulia Solovieva ${ }^{1}$}

\author{
${ }^{1}$ Universidad Autónoma de Puebla, México.
}

\begin{abstract}
Resumen
El traumatismo craneoencefálico (TCE) es un problema social de salud que suele producir una serie de importantes afectaciones como incapacidades motoras, problemas comportamentales y cognitivo-intelectuales. Este trabajo tiene como objetivo presentar los resultados de rehabilitación neuropsicológica de un caso de afasia provocado por un traumatismo craneoencefálico. El paciente es un joven varón de 18 años que, tras sufrir una caída y consecuente TCE, cursa con síndrome afásico identificado por la evaluación neuropsicológica como afasia acústico-mnésica según la clasificación luriana. El estudio de tomografía computarizada presenta imagen hipodensa de bordes irregulares poco definidos involucrando temporal y parietal izquierdos e imagen hipodensa en el lóbulo frontal derecho. También se identifica área hipodensa en la región occipto-temporal media. La revaloración acusa una considerable recuperación del lenguaje, la escritura, la lectura y el cálculo.

Palabras-clave: Traumatismo craneoencefálico; afasia acústico-mnésica; evaluación neuropsicológica; neuropsicología luriana.
\end{abstract}

\section{Résumé}

Le traumatisme crânien est un problème de santé publique qui a des répercussions au niveau cognitif, comportemental et moteur. Le présent article vise à présenter les résultats d'un programme de réhabilitation d'un patient devenu aphasique suite à un traumatisme crânien. Le patient est un jeune homme âgé de 18 ans, souffrant d'aphasie acoustique mnésique, d'après la classification de Luria. La tomodensitométrie a mis en évidence des hypodensités au niveau du lobe temporal et pariétal gauche, et du lobe frontal droit. Une hypodensité a également été trouvée dans la région occipito-pariétale médiane. Après la réhabilitation, le patient a montré une amélioration du langage, de l'écriture et des habiletés arithmétiques.

Mots clés : Traumatisme crânien; aphasie mnésique acoustique; evaluation neuropsychologique ; neuropsychologie Lurienne.

\section{Resumo}

O traumatismo cranioencefálico (TCE) é um problema social de saúde que produz uma série de prejuízos, como incapacidades motoras, problemas comportamentais e cognitivo-intelectuais. Esse trabalho tem como objetivo apresentar os resultados da reabilitação neuropsicológica de um caso de afasia provocado por um TCE. O paciente é um jovem do sexo masculino de 18 anos que, após uma queda e conseqüente YCE, apresenta uma síndrome afásica identificada pela avaliação neuropsicológica como afasia acústico-mnésica segundo a classificação luriana. $\mathrm{O}$ estudo de tomografia computadorizada apresenta uma imagem hipodensa de bordas irregulares pouco definidas envolvendo o lobo parietal e temporal esquerdo e uma imagem hipodensa no lobo frontal direito. Também se identifica uma área hipodensa na região ocipto-temporal medial. A reavaliação acusa uma considerável recuperação da linguagem, da escrita, da leitura e do cálculo.

Palavras-chave: Traumatismo cranioencefálico; afasia acústico-mnésica; avaliação neuropsicológica; neuropsicologia luriana.

Artículo recibido: 11/04/2010; Artículo revisado: 21/12/2010; Artículo aceptado: 08/04/2011.

Jamile Chastinet, Maestría en Diagnóstico y Rehabilitación Neuropsicológica, Facultad de Psicología, Universidad Autónoma de Puebla. Caio Morais, Maestría en Diagnóstico y Rehabilitación Neuropsicológica, Facultad de Psicología, Universidad Autónoma de Puebla. Yulia Solovieva, Maestría en Diagnóstico y Rehabilitación Neuropsicológica, Facultad de Psicología, Universidad Autónoma de Puebla.

Correspondencia relacionada con este artículo debe ser enviada a: Yulia Solovieva, Benemérita Universidad Autónoma de Puebla, Puebla, México, C.P. 72000 .

E-mail: yulia.solovieva@ fsic.buap.mx

DOI: $10.5579 / \mathrm{rnl} .2011 .0049$ 


\section{Abstract}

Brain trauma is a social health problem that has motor, behavioural and cognitive associated consequences. The present article aims at presenting the results of the rehabilitation of an aphasic patient due to brain trauma. The patient is an 18year-old male suffering from acoustic-mnestic aphasia, according to Luria's classification. The CT scan shows hypodense images involving the left temporal and parietal and the right frontal lobes. Also, a hypodense image is found in the medial occipital-parietal region. After rehabilitation, the patient shows improved language, writing, reading and arithmetic abilities.

Keywords: Brain trauma; acoustic-mnestic aphasia ; neuropsychological assessment; Lurian neuropsychology.

El trauma craneoencefálico (TCE) es un problema de salud mundial que produce incapacidades motoras, del comportamiento o en la esfera cognitiva (Guzman, 2008). Existen importantes semejanzas entre los cuadros consecuentes a traumatismos cerebrales. Debido a la configuración del cráneo, el impacto del golpe generalmente tiende a transmitirse hacia las estructuras de la base del lóbulo frontal y hacia la parte anterior y medial del lóbulo temporal. El síndrome postraumático por lo común es similar al que aparece en caso de daño en la base de los lóbulos frontales y hacia la parte anterior y la cara interna de los lóbulos temporales (Ardila \& Ostrosky-Solís, 2007).

Existen diferentes criterios para distinguir o clasificar los TCE los cuales se basan en si hay o no fractura del cráneo, si se trata de un traumatismo abierto o cerrado, si existe sólo el efecto conmocional, el efecto del impacto, de la aceleración, y la desaceleración de la masa encefálica o si hay una lesión traumática del tejido cerebral (Ardila \& OstroskySolís, 2007).

Los traumatismos craneales eran clasificados tradicionalmente por conmoción (o concusión) y contusión. El primero se refiere a la pérdida de conciencia de corta duración, sin alteraciones neurológicas y sin daño anatómico. A esta idea de ausencia de lesión estructural se añadió posteriormente $\mathrm{y}$ - sin fundamento científico - la de breve duración de la inconsciencia y falta de signos focales como indicio de una alteración puramente funcional del encéfalo. Este concepto actualmente es insostenible, ya que se ha comprobado que en estos casos puede haber daño estructural leve, con ruptura de axones y contusión hemorrágica de la corteza. La contusión es la perdida prolongada de consciencia, con signos neurológicos anormales y lesión anatómica del encéfalo (Martínez, 1998). Esta definición de contusión implicaría que si no hay trastornos prolongados de la consciencia no hay entonces lesión estructural, lo cual sería falso, pues contusiones hemorrágicas de la corteza sin trastornos de la consciencia prolongados o severos son frecuentes (Martínez, 1998).

Posteriormente los términos utilizados pasaron a ser los de TC leve y TC severo sin entrar en detalles anatómicos. Hace quince años Strich y Oppenheimer (Oxford) y las investigaciones de Jennett y Teasdale (Glasgow), empezaron a clasificarse de acuerdo con el estado de conciencia del paciente, el cual se puede clasificar con la "Escala de Coma" siendo quince la puntuación normal y tres la peor. Esta escala fue muy bien aceptada mundialmente (Martínez, 1998): TC leve (puntuación de la escala de coma de Glasgow de 13 a 15), TC moderado ( 9 a 12) y TC severo (8 o menos) (Martínez, 1998).

Las lesiones compresivas más frecuentes son por hematoma epidural y subdural. El hematoma epidural se forma entre la duramadre y la calota por ruptura de arteriolas que entran al hueso, o de la meníngea media o sus ramas lesionadas por una fractura, o por lesión de los senos venosos de la duramadre. Se manifiesta por deterioro de la consciencia o por signos de hernia tentorial (síndrome úncal) dentro de las primeras 24 horas siguientes al traumatismo, pero puede tardar días o hasta semanas en manifestarse. El hematoma subdural agudo se forma por sangrado de pequeños vasos corticales de área de lesión focal (contusión hemorrágica) que rodean al ala menor del esfenoides o de otros sitios de contusión o de alguna vena sagital, de las que van de la corteza al seno longitudinal, rota por la sacudida de la cabeza (Martínez, 1998). Las consecuencias neuropsicológicas de pacientes que han sufrido TCE usualmente se clasifican en tres categorías: 1) déficits cognoscitivo-intelectuales; 2) amnesia anterógrada; 3 ) cambios de personalidad (puerilidad, desinhibición, agresividad, etc., o por el contrario, apatía, depresión y juicio, entre otros) (Ardila \& Ostrosky-Solís, 2007).

El presente trabajo tiene como objetivo presentar los resultados de una intervención neuropsicológica de un caso de afasia provocado por un traumatismo craneoencefálico. La evaluación, el diagnóstico y los métodos de rehabilitación se apoyan en el aparato teórico-metodológico de la escuela luriana de neuropsicologia.

\section{La Afasiología Luriana}

Se pueden citar diferentes maneras de conceptuarse las afasias que comúnmente se consideran como una alteración en la capacidad para utilizar el lenguaje. La forma en que será abordada la afasia en este estudio será la propuesta de la escuela neuropsicológica histórico-cultural, en la cual su principal representante, A.R. Luria (1947). Desde esta postura la afasia se comprende como una alteración sistémica del lenguaje que, en sujetos diestros, surge ante lesiones corticales locales del hemisferio izquierdo conduciendo a la desaparición de uno u otro eslabón (factor) y que se manifiesta en síndromes específicos que caracterizan a los diferentes tipos de alteración del lenguaje. Ampliando este concepto, Tsvetkova (1988) refiere que la afasia no es solamente una alteración del lenguaje, sino que un síndrome complejo en donde se alteran otros procesos psicológicos tales como la percepción, la memoria, el pensamiento, etc. Así, esta autora define la afasia como una alteración sistémica del lenguaje que resulta de lesiones locales del cerebro, involucrando diferentes niveles de su organización que influyen sobre sus relaciones con otros procesos psíquicos y conducen a la desintegración de toda la esfera psíquica del hombre, alterando, en primer lugar, la función comunicativa del lenguaje. Para esta concepción la afasia incluye cuatro componentes: la alteración propia del lenguaje y de la comunicación verbal, la alteración de otros procesos psíquicos, cambios en la personalidad y la reacción hacia la enfermedad (Quintanar, 1999). 
La afasiología luriana es la que abarca con mayor amplitud todo el complejo de factores en que están implicados en los síndromes afásicos. No se limita a percibirlos como solo una alteración en el lenguaje, sino que busca descubrir el mecanismo básico de la lesión a partir del análisis de los factores propuestos en la teoría construida por esta escuela.

Asimismo, para la mejor comprensión de los tipos de afasia propuestos por Luria es necesario tener en cuenta la teoría de la neuropsicología histórico-cultural.

\section{Los Factores y Los Síndromes Afásicos}

Luria propuso una nueva concepción de "síndrome" de acuerdo a la cual es la alteración de unas funciones y la conservación de otras, donde las funciones afectadas comparten un factor común, mientras que las conservadas no incluyen dicho factor en su estructura. Así, el síndrome está integrado por un conjunto de síntomas, los cuales constituyen el efecto sistémico del factor afectado, conformando el cuadro clínico que puede incluir alteraciones del lenguaje expresivo e impresivo, de la lectura y de la escritura, de la memoria, de la actividad intelectual, etc. Esto quiere decir que un síndrome afásico no se relaciona únicamente con la alteración del lenguaje, sino que puede relacionarse con alteraciones de los demás procesos psicológicos (Quintanar \& Solovieva, 2002).

La clasificación de la afasia propuesta por Luria tiene una base psicofisiológica. En este modelo, la lesión de determinados sectores cerebrales conduce a la pérdida o debilitamiento del trabajo específico (factor) que realiza cada uno de ellos. Así, el tipo de afasia depende del factor (mecanismo neuropsicológico) que se vea afectado (Solovieva \& Quintanar, 2005).

El concepto de factor fue introducido por primera vez en la neuropsicología por Luria en 1947-1948 en los trabajos "Afasia traumática" y "Rehabilitación de las funciones después de traumatismos de guerra" y es fundamental para toda la concepción teórica de la neuropsicología elaborada por Luria. A partir de él, este autor logró superar la identificación inmediata de los conceptos psicológicos en el nivel morfológico, lo que Pavlov consideraba como el error básico del psicomorfologismo . Con el concepto de factor Luria definía "'la función propia' de una $u$ otra estructura cerebral, el principio o medio determinado (modus operandis) de su trabajo" (Xomskaya, 2002). Cada zona cerebral participante del sistema funcional que se encuentra en la base de la función neuropsicológica superior es responsable de un factor determinado y su destrucción (o cambio patológico) conduce a la alteración del trabajo del sistema funcional correspondiente en general (Xomskaya, 2002). En la Tabla 1 se presentan los tipos de afasias, el factor relacionado y su substrato neuroanatómico.

\section{La Afasia Acústico-Mnésica}

La afasia acústico-mnésica, según Tsvetkova (1988), surge como consecuencia de lesiones en las áreas 21 y 37 de Brodmann, es decir, la segunda circunvolución temporal izquierda. Para la adecuada comprensión de esta forma de afasia es necesario tener presente las características de las áreas cerebrales cuya lesión la provoca. Estas regiones corticales se relacionan no solo con el analizador auditivo, sino también visual, y con las regiones límbicas del cerebro, responsables de los procesos de memoria. Fundamentalmente se encuentra una alteración de las interrelaciones entre dos analizadores: acústico y visual. En esta forma de afasia subyacen la alteración de la memoria auditivo-verbal, disminución del volumen de la memoria auditiva y alteraciones en las representaciones visuales. Aparecen defectos en la comprensión del lenguaje y en la denominación. Se altera de manera secundaria el lenguaje espontaneo, el cual se acompaña de una cantidad considerable de parafasias. Sin embargo, el oído fonemático se encuentra conservado (Tsvetkova, 1996). En las tareas de repetición, el paciente sustituye las oraciones con estructuras sintéticas complejas por oraciones sencillas que no reflejan el significado de las oraciones originales (Solovieva \& Quintanar, 2005).

El cuadro clínico se manifiesta como una alteración en la comprensión del lenguaje y una pérdida del sentido de las palabras; se encuentra una imposibilidad para denominar objetos y una desintegración del lenguaje espontáneo. La escritura y lectura pueden hallarse relativamente conservadas (Tsvetkova, 1996). Luria observó que las dificultades en el lenguaje son en particular evidentes cuando se incrementa la cantidad de información verbal, y por esto consideró que el mecanismo (factor) central de esta forma de afasia es la alteración en la memoria acústico-verbal operativa (Tsvetkova, 1996), es decir, la capacidad de mantener informaciones verbales en la memoria operativa y manipularla.

Solovieva y Quintanar (2005) sustentan la hipótesis de Luria $(1947,1969)$ acerca de la presencia de un único factor alterado en cada tipo de afasia. En el cuadro de la afasia acústico-mnésica el factor debilitado es la memoria audioverbal únicamente, no incluyendo la alteración de las imágenes objetales como lo señala Tsvetkova (1988). En el caso en que se incluyera también las imágenes internas habría un cuadro mixto de afasia acústico-mnésica y amnésica y participarían los dos mecanismos neuropsicológicos: la retención audio-verbal y las imágenes objetales (retención visuo-espacial) (Solovieva \& Quintanar, 2005).

\section{Caso Clínico}

El paciente J.E., del sexo masculino, diestro, de 18 años cursaba el primer semestre de la carrera de informática. Vive con los padres en una colonia considerada de clase social baja en una capital mexicana. Su padre trabaja como obrero y su madre se dedica a los cuidados del hogar. Ambos tienen baja escolaridad (primaria completa). Sufrió, el 30 de noviembre del 2008, una caída de su propia altura contundiéndose en el cráneo y presentó pérdida del estado de alerta, pasando 12 horas posteriores sin reacción al medio. El paciente obtuvo 10 puntos en la escala de coma de Glasgow (TCE moderado). Hubo presencia de crisis convulsivas y vómitos. La tomografía computarizada, realizada en diciembre de 2008, revela un hematoma epidural temporoparietal izquierdo (figura 1), por lo cual es intervenido quirúrgicamente.

En marzo del 2009 se realiza una nueva tomografía que indica imagen hipodensa de bordes irregulares poco definidos que involucra: temporal y parietal izquierdo (figura 2), como también una imagen hipodensa en el lóbulo frontal derecho (figura 3). En esta misma imagen es posible identificar también región hipodensa en la región occiptotemporal media. 
Tabla 1

Clasificación luriana de las afasias, factor relacionado y substrato neuroanatómico

\begin{tabular}{ccc}
\hline Forma de afasia & Factor & Lesión \\
\hline Afasia motora aferente & Cinestésico & Parietales inferiores \\
\hline Afasia motora eferente & Melodía cinética & Premotores \\
\hline Afasia sensorial & Oído fonemático & Temporales \\
\hline Afasia dinámica & Lenguaje interno & Frontales \\
\hline Afasia semántica & Síntesis espaciales & TPO \\
\hline Afasia amnésica & Imagen objetal & Temporo-occipitales \\
\hline Afasia acústico-mnésica & Memoria audio-verbal (volumen) & Temporales \\
\hline
\end{tabular}

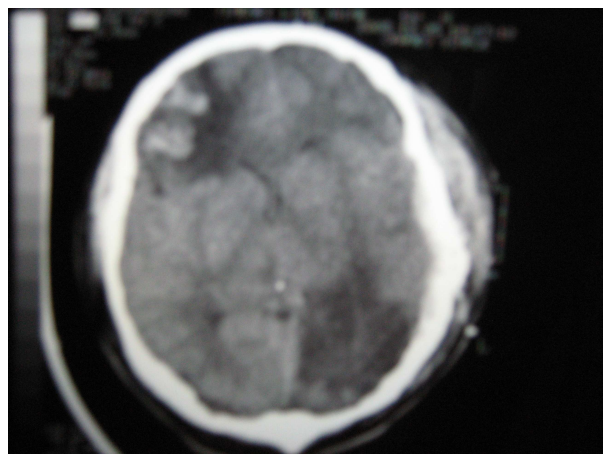

Figura 1. Tomografía realizada en diciembre del 2008.

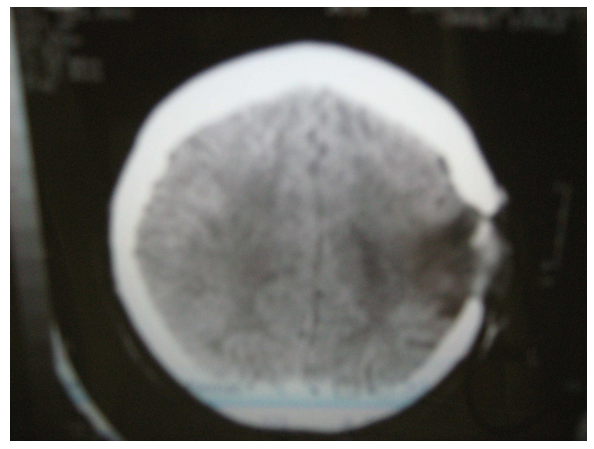

Figura 2. Tomografía realizada en marzo del 2009

\section{Procedimiento}

Inicialmente se realizó la evaluación neuropsicológica del paciente a través de protocolos neuropsicológicos elaborados a partir de la propuesta histórico-cultural. En función de los datos iniciales se determinó un diagnóstico de acuerdo a la neuropsicología luriana. A partir de estos datos fue construido un programa de rehabilitación adecuado a la recuperación de las funciones neuropsicológicas siguiendo los presupuestos de Luria y Tsvetkova (Luria, 1947; Tsvetkova, 1985; Tsvetkova, 1988; Luria \& Tsvetkova, 1981). Después de la aplicación de dicho programa, fue realizada una nueva evaluación neuropsicológica con el objetivo de investigar los resultados del programa rehabilitatório.

Para la primera evaluación fueron utilizadas las siguientes pruebas: Evaluación Neuropsicológica Breve para Adultos (Quintanar \& Solovieva, 2009), descrita en la Tabla 2, protocolo "Diagnóstico Clínico Neuropsicológico de la Afasia Puebla-Sevilla" (Quintanar, Solovieva \& León-Carrión, 2002; 2011), presentada en la Tabla 3, tareas del Protocolo de

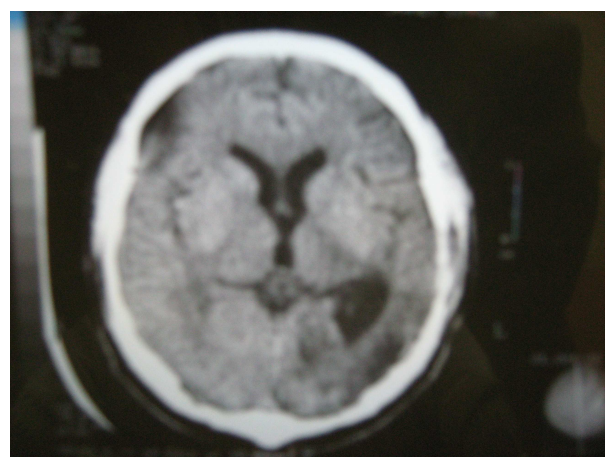

Figura 3. Tomografía realizada en marzo del 2009

evaluación de las funciones visuales y espaciales (Solovieva \& Quintanar, no publicado), tareas del protocolo para la evaluación de la imágenes internas (Quintanar \& Solovieva, 2003) y tareas de verificación del éxito escolar en la escuela primaria (Quintanar \& Solovieva, 2003).

El "Diagnóstico Clínico Neuropsicológico de la Afasia Puebla-Sevilla" (Quintanar et al., 2011) se basa en los mismos analizadores que constituyen los factores neuropsicológicos lurianos. En este caso se investiga específicamente la participación de cada uno de ellos en el lenguaje.

Las tareas seleccionadas del protocolo de evaluación de las funciones visuales y espaciales (Solovieva \& Quintanar, 2003) se asemejan a las descritas en el apartado de análisis y síntesis espaciales y fueron aplicadas con el objeto de investigar mejor este factor. Las del protocolo para la evaluación de las imágenes internas (Quintanar, 1996) se constituyen en tareas relacionadas a la percepción y comprensión de imágenes incompletas y estilizadas para investigar la conformación de imágenes internas. Las tareas de verificación del éxito escolar en la escuela primaria 
Tabla 2

Estructura general de la Evaluación Neuropsicológica Breve para Adultos (Quintanar \& Solovieva, 2009)

\begin{tabular}{|c|c|c|c|}
\hline Analizador & Función & Zona cerebral & Tareas \\
\hline $\begin{array}{l}\text { I. Analizador } \\
\text { Cinestésico }\end{array}$ & $\begin{array}{l}\text { Garantiza la sensibilidad táctil fina, así } \\
\text { como la precisión de posturas y poses; } \\
\text { en la articulación del lenguaje garantiza } \\
\text { la diferenciación de los sonidos verbales } \\
\text { de acuerdo al punto y modo de su } \\
\text { producción motora. }\end{array}$ & $\begin{array}{l}\text { Zonas parietales del } \\
\text { hemisferio izquierdo. }\end{array}$ & $\begin{array}{l}\text { 1) reproducción de posiciones de los } \\
\text { dedos. } \\
\text { 2) reconocimiento de objetos. } \\
\text { 3) reproducción de posiciones del } \\
\text { aparato fono- } \\
\text { articulatorio. } \\
\text { 4) repetición de sílabas y sonidos. } \\
\text { 5) determinación de la cantidad de } \\
\text { sonidos en palabras. }\end{array}$ \\
\hline $\begin{array}{l}\text { II. Organización } \\
\text { Cinéticade los } \\
\text { Movimientos }\end{array}$ & $\begin{array}{l}\text { Garantiza el paso fluente de un } \\
\text { movimiento a otro, } \\
\text { inhibe el eslabón motor anterior para el } \\
\text { paso flexible } \\
\text { al eslabón motor posterior. }\end{array}$ & $\begin{array}{l}\text { Zonas premotoras del } \\
\text { hemisferio izquierdo. }\end{array}$ & $\begin{array}{l}\text { 1) organización recíproca de las manos } \\
\text { (sin } \\
\text { lenguaje y con lenguaje). } \\
\text { 2) copiar y continuar una secuencia } \\
\text { gráfica. }\end{array}$ \\
\hline $\begin{array}{l}\text { IV. Funciones } \\
\text { Mnésicas }\end{array}$ & $\begin{array}{l}\text { Garantiza la estabilidad de las huellas } \\
\text { mnésicas } \\
\text { (volumen de percepción) en las } \\
\text { modalidades audio- } \\
\text { verbal, visual y táctil en condiciones de } \\
\text { interferencia } \\
\text { homo y heterogénea. }\end{array}$ & $\begin{array}{l}\text { Audio-verbal: Zonas } \\
\text { temporales medias del } \\
\text { hemisferio izquierdo; } \\
\text { Visual: Zonas } \\
\text { occipitales; Táctil: } \\
\text { Zonas parietales. }\end{array}$ & $\begin{array}{l}\text { 1) reproducir posiciones de los dedos en } \\
\text { la mano } \\
\text { contraria. } \\
\text { 2) retención audio-verbal involuntaria y } \\
\text { voluntaria. } \\
\text { 3) retención viso-motora. } \\
\text { 4) retención audio-verbal con } \\
\text { interferencia } \\
\text { heterogénea. }\end{array}$ \\
\hline
\end{tabular}

Garantiza la percepción y producción adecuada de

V. Análisis y rasgos esenciales y su ubicación y las

Síntesis

Espaciales

Simultáneas relaciones

espaciales entre los elementos de la situación de la

forma general, de los aspectos métricos y de las proporciones de objetos.
Garantiza el proceso de ejecución de una tarea de acuerdo al objetivo, instrucción o regla establecido.
Análisis: TPO
1) comprensión de órdenes.
(hemisferio izquierdo).
2) esquema corporal.
3) comprensión de oraciones.
Síntesis: TPO
4) percepción de números y letras.
(hemisferio derecho).

\author{
Es investigado a través de las \\ ejecuciones en \\ todas las tareas, las cuales se espera que \\ sean \\ organizadas, debidamente planeadas, \\ reguladas y \\ auto-corregidas.
}

Sectores prefrontales del hemisferio izquierdo.
(Quintanar \& Solovieva, 2003) se constituyen en actividades para la investigación de la lectura escritura y del cálculo. Para verificar posibles daños causados por la lesión frontal derecha fue aplicada la Batería de Funciones Frontales y Ejecutivas (Flores, Ostrosky-Solís \& Lozano, 2008). Los resultados no apuntaron compromisos neuropsicológicos causados por tal lesión.

Las tareas seleccionadas del protocolo de evaluación de las funciones visuales y espaciales (Solovieva \& Quintanar, 2003) se asemejan a las descritas en el apartado de análisis y síntesis espaciales y fueron aplicadas con el objeto de investigar mejor este factor. Las del protocolo para la evaluación de las imágenes internas (Quintanar, 1996) se constituyen en tareas relacionadas a la percepción y comprensión de imágenes incompletas y estilizadas para investigar la conformación de imágenes internas. Las tareas de verificación del éxito escolar en la escuela primaria (Quintanar \& Solovieva, 2003) se constituyen en actividades para la investigación de la lectura escritura y del cálculo. 
Tabla 3

Estructura general de la “Evaluación Clínico-Neuropsicológica de la Afasia Puebla-Sevilla” (Quintanar et al., 2011).

\begin{tabular}{|c|c|c|}
\hline Analizador & Función & Tareas \\
\hline $\begin{array}{l}\text { I. Factor Melodía } \\
\text { Cinética }\end{array}$ & $\begin{array}{l}\text { Garantiza el paso fluente de } \\
\text { un movimiento a otro, inhibe } \\
\text { el eslabón motor anterior } \\
\text { para el paso flexible al } \\
\text { eslabón motor posterior. }\end{array}$ & $\begin{array}{l}\text { 1) comprensión de oraciones que se diferencian en base al género y número. } \\
\text { 2) repetición de series de sílabas. } \\
\text { 3) repetición de pares de palabras. } \\
\text { 4) elaboración de oraciones simples de acuerdo a los cuadros presentados. }\end{array}$ \\
\hline $\begin{array}{c}\text { II. Factor } \\
\text { Cinestésico }\end{array}$ & $\begin{array}{l}\text { Garantiza la diferenciación } \\
\text { de los sonidos verbales de } \\
\text { acuerdo al punto y modo de } \\
\text { su producción motora. }\end{array}$ & $\begin{array}{l}\text { 1) discriminación de sonidos consonánticos cercanos por punto y modo de } \\
\text { articulación. } \\
\text { 2) comprensión de palabras (con sonidos consonánticos cercanos por punto y } \\
\text { modo de articulación). } \\
\text { 3) repetición de pares de sílabas que contienen sonidos consonánticos cercanos por } \\
\text { punto y modo de articulación. } \\
\text { 4) repetición de pares de palabras que contienen sonidos consonánticos cercanos } \\
\text { por punto y modo de articulación. }\end{array}$ \\
\hline $\begin{array}{l}\text { III. Factor Oído } \\
\text { Fonemático }\end{array}$ & $\begin{array}{l}\text { Garantiza la diferenciación } \\
\text { de los sonidos verbales del } \\
\text { idioma dado de acuerdo a las } \\
\text { oposiciones fonemáticas }\end{array}$ & $\begin{array}{l}\text { 1) discriminación de sonidos consonánticos opuestos por oído fonemático. } \\
\text { 2) comprensión de palabras que contienen sonidos consonánticos opuestos por } \\
\text { oído fonemático. } \\
\text { 3) repetición de pares de sílabas que contienen sonidos consonánticos opuestos por } \\
\text { oído fonemático. } \\
\text { 4) repetición de pares de palabras que contienen sonidos consonánticos opuestos } \\
\text { por oído fonemático. }\end{array}$ \\
\hline $\begin{array}{l}\text { IV. Factor } \\
\text { Análisis y Síntesis } \\
\text { Simultáneas } \\
\text { Espaciales }\end{array}$ & $\begin{array}{l}\text { Garantiza la adecuada } \\
\text { comprensión de de los } \\
\text { elementos cuasi-espaciales } \\
\text { del lenguaje, así como la } \\
\text { adecuada utilización de } \\
\text { preposiciones. }\end{array}$ & $\begin{array}{l}\text { 1) comprensión de órdenes que contienen relaciones espaciales. } \\
\text { 2) comprensión de oraciones que contienen relaciones cuasi-espaciales tanto } \\
\text { comparativas como temporales. } \\
\text { 3) comprensión de oraciones que contienen relaciones cuasi-espaciales tanto } \\
\text { pasivas como genitivas. } \\
\text { 4) elaboración de oraciones que incluyan relaciones cuasi-espaciales y de } \\
\text { causalidad. }\end{array}$ \\
\hline $\begin{array}{l}\text { V. Retención } \\
\text { Visuo-verbal }\end{array}$ & $\begin{array}{l}\text { Garantiza la formación y } \\
\text { adecuada utilización de } \\
\text { conceptos. }\end{array}$ & $\begin{array}{l}\text { 1) comprensión de palabras cercanas semánticamente y por su imagen objetal. } \\
\text { 2) comprensión de palabras en grupos semánticos definidos (verduras y animales). } \\
\text { 3) denominación de objetos cercanos semánticamente y por su imagen objetal). } \\
\text { 4) denominación de objetos en grupos semánticos definidos (verduras y animales). }\end{array}$ \\
\hline $\begin{array}{l}\text { VI. Factor } \\
\text { Retención Audio- } \\
\text { Verbal }\end{array}$ & $\begin{array}{l}\text { Garantiza la estabilidad de } \\
\text { las huellas mnésicas } \\
\text { (volumen de percepción) en } \\
\text { la modalidad audio-verbal. }\end{array}$ & $\begin{array}{l}\text { 1) comprensión de oraciones largas. } \\
\text { 2) comprensión de verbos cercanos semánticamente. } \\
\text { 3) repetición de oraciones largas; } \\
\text { 4) denominación de verbos cercanos semánticamente. }\end{array}$ \\
\hline $\begin{array}{l}\text { VII. Factor } \\
\text { Dinámico }\end{array}$ & $\begin{array}{l}\text { Garantiza la capacidad de } \\
\text { iniciar y mantener } \\
\text { espontáneamente la } \\
\text { producción verbal. }\end{array}$ & $\begin{array}{l}\text { 1) narración. } \\
\text { 2) comprensión de un texto. } \\
\text { 3) series inversas. } \\
\text { 4) elaboración de oraciones complejas de acuerdo a los cuadros temáticos. }\end{array}$ \\
\hline
\end{tabular}

Para verificar posibles daños causados por la lesión frontal derecha fue aplicada la Batería de Funciones Frontales y Ejecutivas (Flores, Ostrosky-Solís, \& Lozano, 2008). Los resultados no apuntaron compromisos neuropsicológicos causados por tal lesión.

\section{Resultados de la Evaluación Incial y Diagnóstico}

El diagnóstico se realizó según la investigación del funcionamiento de los factores neuropsicológicos lurianos y sus reflejos en las funciones psicológicas superiores del paciente. Fallas en determinado factor provoca consecuencias específicas en cada una de las funciones complejas como lenguaje, escritura, lectura, calculo, funciones ejecutivas, etc. En las Tablas 4 y 5 se presentan los resultados por factores y por funciones respectivamente. El paciente presentó algunos déficits cognoscitivo-intelectuales citados por Ardila y Ostrosky-Solís (2007). 
Tabla 4

Resultados de la evaluación inicial por factor neuropsicológico Luriano

Factor

Analizador Cinestésico Movimientos

Factor Oído Fonemático

Retención Visual

Retención audio-verbal

Análisis y Síntesis

Espaciales Simultáneas

Programación y control

de la actividad consciente

\section{Resultados}

Se observó un funcionamiento adecuado: es capaz de reconocer objetos colocados en la palma de su mano con los ojos cerrados, así como reproducir con éxito las posiciones de los dedos y del aparato fono-articulatorio, aunque en estas últimas tareas presentó cierta dificultad con el control de sus movimientos de la lengua.

En el plano motor, presenta movimiento fluido y sin perseveraciones. Es capaz de llevar a cabo adecuadamente una secuencia gráfica. En su lenguaje, lectura o escritura no hay presencia de perseveraciones o inercias.

Presentó un adecuado funcionamiento, pues logró identificar imágenes correspondientes a diferentes palabras solicitadas. Pudo llevar a cabo instrucciones sencillas y señalar imágenes correspondientes a oraciones cortas.

Logra recordar series de letras y símbolos presentados visualmente. Presenta buena conformación de las imágenes internas. Logra reconocer y completar figuras incompletas y logra plasmar las características esenciales de los objetos en sus dibujos.

No logra mantener el volumen de información presentada oralmente, por lo que es necesario ofrecer la información de manera segmentada. Las dificultades de comprensión de oraciones, están relacionadas principalmente con el volumen de información. En el recuerdo de oraciones hay la ausencia, principalmente de sustantivos. En la repetición y evocación de series de palabras no es posible realizarla con la presentación oral de la palabra, es necesaria su presentación por escrito. Las series de palabras cercanas fonologicamente produce dificultad, pero la mayor dificultad es presentada ante series de palabras cercanas semánticamente.

En el plano material mostró un adecuado funcionamiento: logra ubicar correctamente los objetos concretos en determinada posición espacial con respecto a otros. También ubica objetos con relación a su cuerpo, presenta noción de derecha e izquierda, revelando un buen funcionamiento a nivel corporal. En el plano perceptual también presenta un buen funcionamiento ya que presenta una adecuada orientación espacial revelada en su actividad grafica (ubica los elementos en la posición adecuada). No obstante, en el plano verbal, se hace más difícil la realización de las tareas ya que presenta dificultad en comprender las estructuras lógico-gramaticales (temporales, pasivas y genitivas), y presenta dificultades en la elaboración de oraciones. Estas dificultades son disminuidas con la segmentación de la información. Este dato relaciona esta dificultad con la debilidad del factor de retención audio-verbal. Presentase en buen funcionamiento, pues se mostró capaz de llevar a cabo todas las tareas propuestas, regular y controlar su conducta y no se presenta impulsivo. Hay la realización de un análisis visual adecuado hacia los elementos de cuadros presentados y es capaz de verificar sus ejecuciones.

Tabla 5

Resultados de la evaluación inicial por función

\begin{tabular}{cl}
\hline Función & \multicolumn{1}{c}{ Resultados } \\
\hline \multirow{2}{*}{ Lectoescritura } & $\begin{array}{l}\text { Está relativamente conservada, siendo posible observar apenas algunos } \\
\text { errores de sustitución de letras en la escritura (por ejemplo, l por r) y también } \\
\text { lenificación en la lectura (realiza lectura fonológica). }\end{array}$ \\
\hline \multirow{2}{*}{ Cálculo } & $\begin{array}{l}\text { Está conservado, no obstante hay dificultad en llevar a cabo la resolución de } \\
\text { problemas, ya que se olvida de la pregunta a que se debe contestar (inicia las } \\
\text { operaciones necesarias para la resolución, pero se olvida cual debe ser el } \\
\text { próximo paso, siendo necesario el regreso al enunciado de la cuestión). }\end{array}$ \\
\hline \multirow{2}{*}{ Lenguaje } & $\begin{array}{l}\text { Presenta problemas en la denominación y en la comprensión del lenguaje. } \\
\text { Comete parafasias semánticas. Sus dificultades son más evidentes cuando se } \\
\text { incrementa la cantidad de información verbal. }\end{array}$ \\
\hline \multirow{2}{*}{ Funciones ejecutivas } & $\begin{array}{l}\text { No fueron detectados problemas en las funciones ejecutivas. El paciente es } \\
\text { capaz de planear, crear estrategias, monitorear y verificar sus acciones. }\end{array}$ \\
\hline
\end{tabular}


Cabe mencionar acerca de las particularidades del lenguaje expresivo del paciente. La articulación de palabras, después del traumatismo, se presentó muy comprometida. Se observó también cierta dificultad con el control de los movimientos de la lengua. Sin embargo, después de la realización de la terapia física, fue observado en las sesiones de evaluación una considerable mejoría en su articulación. Su lenguaje oral ahora se presenta, en ocasiones, con inadecuada producción de los sonidos de las letras. En su habla hay presencia esporádica de sustituciones cercanas por punto $\mathrm{y}$ modo de articulación (ej: foco por poco, clavos por platos, aretes por adetes), pero estos errores no son sistemáticos $\mathrm{y}$ con la repetición de la palabra el error no se presenta en la mayoría de los casos. Por esta razón, se considera que estas dificultades, ya no muy pronunciadas, no se relacionan con debilidad en algún factor y sin pueden ser decurrentes de la afectación de zonas más profundas del lóbulo parietal y sus conexiones con esta área, que probablemente fueron la causa de la hemiparesia derecha. Se llegó a la conclusión de que dichos problemas se daban en función de la lesión haber atingido una parte profunda del lóbulo parietal interrumpiendo fibras que pasan por la región media temporal y siguen hacia la región parietal, según se ve en la tomografía (Figura 3). Había, así, un compromiso de fibras aferentes periféricas. Es decir, aunque la información sí pudiera ser adecuadamente analizada en la corteza parietal, la transmisión era hecha de forma irregular a este centro. Esta característica enmascaraba la expresión del factor afectado dificultando, la adecuada consideración del estado funcional principalmente de los factores de oído fonemático, cinestésico y audio-verbal. En resumen, se observa que las principales dificultades presentadas por el paciente se relacionaron con el funcionamiento del factor de retención en su modalidad audio-verbal: no logra mantener el volumen de información presentada oralmente, por lo que es necesario ofrecer la información de manera segmentada. Las dificultades de comprensión de oraciones están relacionadas principalmente con el volumen de información. En el recuerdo de oraciones hay la ausencia principalmente de sustantivos. La repetición y evocación de series de palabras no es posible realizarla con la presentación oral, por lo cual es necesario hacerlo por escrito. Las series de palabras cercanas fonológicamente producen dificultad, pero el mayor problema se presentada ante series de palabras cercanas semánticamente.

Así, la evaluación neuropsicológica inicial reveló el compromiso del factor de retención audio-verbal, relacionado con las dificultades en conservar el volumen de la información, la necesidad de segmentación y de repetición de las instrucciones. Lo anterior conlleva a las dificultades que el paciente presenta en su comprensión y en tareas expresivas especialmente en repetición y denominación. Estas dificultades se relacionan con estructuras corticales temporales. En función de la dificultad en la comprensión fue posible observar problemas relacionados con la realización de las tareas del nivel lógico-verbal. Para estas tareas era necesaria la segmentación de la información y en las más complejas la dificultad permanecía. Todo lo anterior indica el cuadro de una afasia acústico-mnésica.

Frente a los resultados finales del proceso evaluativo inicial fue establecido el diagnóstico de afectación del factor de retención audio-verbal lo que provocó el síndrome que constituye la afasia acústico-mnésica según la categorización luriana, ya descritas anteriormente. Fue, entonces, montado un programa de rehabilitación neuropsicológica el cual tuvo como objetivos generales la rehabilitación del factor que evidencia alteración funcional y la rehabilitación de la expresión y comprensión del lenguaje oral y escrito en el paciente. Posteriormente fue realizada una revaloración del caso con la finalidad de verificar los resultados del trabajo realizado.

\section{El Programa de Rehabilitación}

El programa se llevó a cabo entre los meses de agosto de 2009 a enero de 2010, en sesiones de una hora aproximadamente, con un total de 39 sesiones abarcando 3 etapas. Tenía como objetivo general la superación de los efectos reductivos del volumen de percepción y retención del material discursivo, según fue diagnosticado en la evaluación inicial.

La etapa 1 fue destinada al trabajo con la relación imagen-palabra y su objetivo general fue la rehabilitación del vocabulario activo formado por denominaciones objetales incrementando el volumen de percepción y retención del material discursivo. La etapa 2 tuvo como objetivo general la rehabilitación de la retención de palabras presentadas oralmente. La última etapa trabajada fue la 3 que objetivó el incremento de la retención y la comprensión de textos.

\section{ETAPA 1}

Objetivo: establecer la relación imagen-palabra; recuperar relación entre la palabra concreta y la categoría. Se utilizan imágenes objetales conservadas del paciente.

Se trabaja con imágenes dibujadas por el paciente y con palabras escritas. Inicialmente fueron presentadas palabras cortas y frecuentes y se implementó un gradual incremento en el tamaño y disminución del nivel de frecuencia de las palabras.

Tarea 1: Se presenta una tarjeta con una imagen de un objeto. La imagen se acompaña por tres nombres de objetos por escrito (uno de los cuales es correcto) para que el paciente elija la palabra correspondiente. Posteriormente el paciente construye una frase que contenga la palabra dada.

Tarea 2: Se presentan 5 tarjetas con imágenes de objetos (las de la tarea anterior) y sus respectivos nombres. El paciente relaciona la palabra con la imagen correspondiente y organiza estos objetos iniciando los cuatro grupos de las categorías diferentes. Gradualmente la cantidad de objetos y categorías respectivas incrementa. Al final se conforma una tabla con diversas categorías trabajadas (por ejemplo, animales, objetos de la cocina, partes del cuerpo, instrumentos musicales y deportes).

Tarea 3: Se presenta al paciente el nombre de un objeto, y el paciente debe encontrar la imagen correspondiente entre otras (se utilizan dos objetos que no se relacionan con el nombre y otros tres que corresponden con nombre, pero que son presentados con características (formas, colores, ángulos, etc.) diversas. Se utilizan las mismas imagenes de las tareas anteriores. El paciente debe elegir las imágenes que corresponden a la palabra. Cuando encuentre las tres objetos de las representaciones diferentes para la misma palabra, debe establecer las semejanzas y diferencias entre ellos.

Tarea 4: Se le da al paciente una tarjeta en blanco y se nombra una de las categorías trabajadas anteriormente (una a la vez). Se le pide al paciente que dibuje un objeto (instrumento musical) que se ha imaginado. Después él debe 
decir en voz alta la palabra dibujada y escribirla junto al dibujo. El paciente dibuja otro objeto de una categoría diferente y lo denomina (formando diversas categorías diferentes). Posteriormente el paciente tiene que dibujar más elementos para agregar a cada categoría. El paciente denomina todos los objetos junto con el psicólogo.

Tarea 5: En cada una de las categorías trabajadas el paciente intenta recuperar la mayor cantidad de palabras (objetos concretos). Se analizan todas las características de todos los objetos dentro de las categorías. Después se destacan las semejanzas y diferencias para formar grupos (si esto es posible) específicos dentro de la misma categoría.

Tarea 6: Se presentan las palabras ya trabajadas y el paciente debe ponerlas en una tabla con dos columnas que tengan espacios para agregar un sinónimo y un antónimo a ella. Para encontrar los sinónimos y antónimos se presentan opciones de imágenes en que el paciente tiene que elegir la adecuada.

Tarea 7: Se presenta una lámina temática a partir de la cual el paciente debe construir oraciones que se relacionen con el cuadro, armando las oraciones, con las palabras presentadas en tarjetas.

Tarea 8: Se presenta una lámina temática y sus elementos esenciales se escriben en tarjetas. El paciente construye frases que se relacionen con el cuadro, utilizando cada una de las palabras presentadas.

Tarea 9: Trabajo con la raíz morfológica de la palabra. Se le presenta al paciente un verbo con esta raíz morfológica (se utiliza el contenido de las laminas temáticas presentadas en las tareas anteriores). El paciente debe encontrar el adjetivo y el sustantivo (ejemplo: se presenta la palabra llover, el paciente debe encontrar las palabras lluvioso y lluvia). Después de encontrar las palabras construir frases con ellas. Poner las palabras en una tabla que contenga el espacio para el verbo, el sustantivo y el adjetivo.

\section{ETAPA 2}

Objetivo: aumentar el volumen de la retención audio-verbal.

Tarea 1: Sopa de letras. Se presentan letras recortadas, el paciente tiene que encontrar palabras que ya fueron analizadas anteriormente. Se inicia con la búsqueda de una sola palabra y gradualmente se va aumentando el volumen. Al final el paciente debe decir a qué palabras buscó. (Se utilizan palabras ya trabajadas en las tareas anteriores).

Tarea 2: El paciente debe realizar crucigramas que tengan imágenes para encontrar la palabra correspondiente (como ayuda pueden presentarse tarjetas con tres palabras escritas y el paciente elige la correcta, se utilizan palabras anteriormente trabajadas). El paciente debe escribir una oración que contenga cada palabra del crucigrama. Al final debe decir qué palabras fueron trabajadas en la actividad (las imágenes pueden ser presentadas nuevamente para ayudar el recuerdo).

Tarea 3: Al paciente se le dice una lista de 1, 2, 3, 4 o 5 palabras. El paciente toma las imágenes correspondientes a las palabras presentadas (como si fuera un dictado de imágenes). Al final el paciente verifica si todas las imágenes corresponden a las palabras dictadas por el terapeuta. Finalmente, se le pide al paciente que diga qué palabras fueron trabajadas en la actividad.

Tarea 4: Al paciente se le dictan grupos de 2, 3 y 4 palabras. El paciente debe construir una oración utilizando las palabras dictadas.

Tarea 5: Se le dice al paciente el nombre de un animal, y el paciente debe repetir el animal y agregar el nombre de un

Revista Neuropsicologia Latinoamericana (2011), 3(1), 27-39 otro. El psicólogo repite los dos nombres y agrega otro más. El paciente repite los tres nombres y agrega más uno y así sucesivamente. Este mismo juego se realiza con otras categorías. Se utiliza la opción el la cual el animal siguiente se debe iniciar con la última letra de la palabra anterior (ejemplo: perro - oso).

Tarea 6: Se lee una oración al paciente. Posteriormente se presenta 5 tarjetas con las palabras escritas y el paciente debe encontrar tres palabras que estaban presentes en la oración.

\section{ETAPA 3}

Objetivo: Incrementar la retención y comprensión de textos. Se utilizaron las diversas opciones en las tareas de esta etapa para fortalecer la superación de los efectos reductivos del volumen y retención del material.

Tarea 1: El paciente lee el texto que se presenta en dos formas: textos con imágenes de todos los nombres que aparecen en el texto y textos con espacios en blanco. El paciente debe elegir la imagen adecuada para llenar el espacio en el texto. Se hacen preguntas que ayudan a determinar y analizar el contenido del texto (y las imágenes utilizadas se presentan al paciente para ayudar en la evocación de los elementos del texto). Las imágenes se presentan por separado separadamente para que el paciente construya frases con ellas. Tarea 2: Al leer el texto, el paciente debe dividirlo en párrafos y resumir la idea principal de cada párrafo en una oración seleccionada entre tres opciones. Este procedimiento se acompaña por elección de imagen que le corresponde al párrafo. El paciente agrupa las oraciones en un esquema (plan) único que representa el contenido del texto. El paciente debe agrupar también las imágenes desordenadas de acuerdo al orden de acontecimientos en el texto. Al final, se hacen preguntas y un recuento del texto de forma escrita (oral) con ayuda de las imágenes.

\section{Resultados}

En la revaloración J.E. se muestra orientado en persona, espacio y tiempo. En la evaluación inicial se confundía con el día de la semana o la fecha.

Los resultados de la revaloración se presentan en comparación a los de la evaluación inicial para que se puede visualizar los resultados de la intervención realizada. En las tablas presentadas los símbolos “-” y "X" representan falta de respuesta, los "ل " representan respuestas correctas e las reticencias indican lapsos por búsquedas e intentos de recuerdo.

Las principales dificultades presentadas por el paciente en la evaluación inicial se relacionaron con el funcionamiento del factor de retención en su modalidad audio-verbal. J.E. presentó dificultades en la repetición y evocación de series de palabras, perdiendo el volumen de la información verbal presentada. Presentaba también dificultades en la comprensión de oraciones, que se relacionaban principalmente con el volumen de información. En el recuerdo de oraciones había la ausencia, principalmente de sustantivos (lo mismo pasaba en el recuerdo de un texto). Había dificultad en la denominación por el olvido de las palabras.

En la revaloración, en la evocación de series de palabras a nivel involuntario, el volumen de la información retenida es satisfactorio (aunque con sustitución de palabras por otras más frecuentes, ej: duna por luna). A nivel 
voluntario en la segunda presentación retiene todas las palabras presentadas, con una sustitución (duna por dona). Ante interferencia heterogénea regresa a la misma ejecución que a nivel involuntario (Tabla 6). La denominación de palabras frecuentes se realiza con facilidad. En palabras menos frecuentes presenta dificultades, pero la ayuda fonológica suele ser eficaz (Tabla 7). En la repetición de oraciones largas logra evocarlas algunas veces completamente, pero en otras necesita de repetición o de segmentación siendo la ayuda necesaria para lograr la ejecución completa (Tabla 8). La retención de la información de un texto se presenta con mayor volumen de la información y con presencia de sustantivos concretos, lo cual no se observó en la primera evaluación. Además, el paciente logra comprender oraciones con mayor volumen de información, logrando seguir las instrucciones adecuadamente (Tabla 9).

Tabla 6

Evocación de series de palabras en la ejecución inicial y final Inicial Final

\begin{tabular}{lcccc}
\hline \multicolumn{1}{c}{ Ítems presentados } & Foco-duna-piel & Bruma-gasa-luz & Foco-duna-piel & Bruma-gasa-luz \\
\hline Involuntaria & Gasto - - & --- & Luna-foco & Broma- gasa-luz \\
\hline Voluntaria & - duna - & --- & Gasa-dona-luz & Foco-bruma \\
\hline Repetición & - & - & Foco-dona-piel & Bruma-luz-gasa \\
\hline Interferencia heterogénea & Gasta, toma, gasa & --- & Gasa-bruna-piel & Broma-foco-gasa-luz \\
\hline
\end{tabular}

Tabla 7

Denominación de palabras frecuentes y no frecuentes en la ejecución inicial y final

\begin{tabular}{|c|c|c|}
\hline Ejecución & Inicial & Final \\
\hline Pinzas -Clavo & X X & $\sqrt{ } \sqrt{ }$ \\
\hline Cocodrilo - Lagartija & $(\mathrm{AF}) *$ Coco....lilo $-(\mathrm{AF}) \mathrm{La} \ldots$..jatija & $\sqrt{ } \sqrt{ }$ \\
\hline Camisa - suéter & $\sqrt{ }$ & $\sqrt{\sqrt{ }}$ \\
\hline Persiana - Cortina & $\mathrm{XX}$ & (AF) $\sqrt{ } \sqrt{ }$ \\
\hline Cámara - binoculares & (AF) $\sqrt{ }$ - Bi...loculares & $(\mathbf{A F}) \sqrt{ } \sqrt{ }$ \\
\hline Alcachofa - Coliflor & X X & (AF) $\sqrt{ } \sqrt{ }$ \\
\hline Esparragos - Chícharos & $\mathrm{XX}$ & $(\mathbf{A F}) \sqrt{ }-$ \\
\hline Rábano - tomate & (AF) Ra... banditos $\mathrm{X}$ & $\sqrt{\sqrt{ }}$ \\
\hline Flamingo - Pavo & Fla... mencosi $-\mathrm{Pa} . .$. to & $\sqrt{\sqrt{ }}$ \\
\hline Búfalo - Toro & Bu... faloso - To... rito & $\sqrt{ } \sqrt{ }$ \\
\hline
\end{tabular}

$*(\mathrm{AF})=$ Con ayuda fonológica.

Tabla 8

Evocación de oraciones largas en la ejecución inicial y final

$$
\text { Repetición de oraciones largas }
$$

\begin{tabular}{|c|c|c|}
\hline Oraciones & $1^{\mathrm{a}}$ Ejecución & $2^{\mathrm{a}}$ Ejecución \\
\hline $\begin{array}{l}\text { La pequeña niña sostiene un } \\
\text { vaso de leche en su mano }\end{array}$ & $\begin{array}{l}\text { La pe... pe... pequita niña está } \\
\text { sirviendo un vaso de leche }\end{array}$ & $\begin{array}{l}1^{\text {a) }} \text { La pequeña niña sostiene un vaso de } \\
\text { leche. } \\
\left.2^{\text {a }}\right) \sqrt{ }\end{array}$ \\
\hline $\begin{array}{l}\text { El pintor guarda los pinceles } \\
\text { después de terminar su cuadro }\end{array}$ & $\begin{array}{l}\text { El pintor esta (pausa) aguando... } \\
\text { su... sus pin...pinceles de... el ... } \\
\text { cuadro }\end{array}$ & 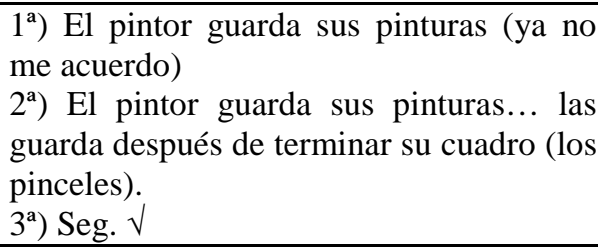 \\
\hline $\begin{array}{l}\text { Los jóvenes juegan a la pelota } \\
\text { en el patio de la casa del vecino }\end{array}$ & $\begin{array}{l}\text { Los jo... no como...como se dice... } \\
\text { (jóvenes) están jugando en ... que... } \\
\text { como se dice. }\end{array}$ & $\begin{array}{l}1^{\text {a })} \text { Los jóvenes juegan a la pelota en la } \\
\text { casa del vecino. } \\
\left.2^{\text {a }}\right) \sqrt{ }\end{array}$ \\
\hline $\begin{array}{l}\text { Los empleados preparan los } \\
\text { documentos para llevarlos al } \\
\text { archivo }\end{array}$ & $\begin{array}{l}\text { Los... como... ese... como... como } \\
\text { se llama (empleados) están } \\
\text { guardando en lo... en las... como se } \\
\text { dice...Ya no me acuerdo. }\end{array}$ & 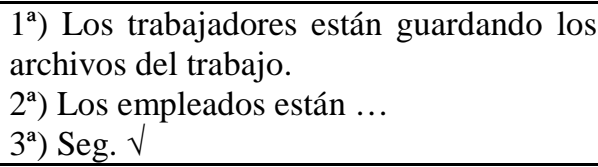 \\
\hline $\begin{array}{l}\text { El arquitecto está revisando los } \\
\text { planos de las casas en } \\
\text { construcción }\end{array}$ & $\begin{array}{l}\text { El arquitecto esta (pausa) como se } \\
\text { dice... esta guardando las artes... las } \\
\ldots \text { No me acuerdo. }\end{array}$ & $\begin{array}{l}1^{\text {a }} \text { El arquitecto esta checando los } \\
\text { archivos del trabajo. } \\
\left.2^{\text {a }}\right) \text { Seg. } \sqrt{ }\end{array}$ \\
\hline
\end{tabular}


Tabla 9

Seguimiento de instrucciones

\begin{tabular}{llll}
\hline \multicolumn{1}{c}{ Ejecución } & Inicial & Final \\
Instrucción & & \\
\hline $\begin{array}{l}\text { Muestra tu ojo derecho con la No sabía qué hacer, se le pidió } \\
\text { mano izquierda }\end{array}$ & $\begin{array}{l}\text { Neñalar solamente partes de la } \\
\text { cara (nariz, oreja). Él se } \\
\text { confundía mucho con las }\end{array}$ & $\sqrt{ }$ \\
\hline $\begin{array}{l}\text { Toca tu oreja izquierda con la } \\
\text { mano izquierda }\end{array}$ & & $\sqrt{ }$ \\
\hline $\begin{array}{l}\text { Con tu mano derecha toca tu } \\
\text { instrucciones. }\end{array}$ & & \\
izquierda toca tu ceja izquierda.
\end{tabular}

En la evaluación inicial del factor de análisis y síntesis espaciales simultáneas en el plano verbal se presentó dificultad en comprender las estructuras lógico-gramaticales (temporales, pasivas y genitivas) y las dificultades en la elaboración de oraciones. Este dato se relacionaba con un efecto secundario de la debilidad del factor de retención audio-verbal. En la revaloración, J.E. logra una mejor comprensión de estructuras lógico-gramaticales complejas (Tabla 10) y no presenta dificultad en la elaboración de oraciones con inclusión de elementos espaciales. Por ejemplo, la señalización de figuras a partir de frases con contenido espacial logró realizarla completamente (Tabla 11). De esta forma, se observa que la mejoría del factor de retención audio-verbal posibilitó la recuperación en la realización de las tareas del factor de análisis y síntesis espacial simultaneas en el plano verbal.

Tabla 10

Comprensión de estructuras lógico-gramaticales complejas, ejecución inicial y final

\begin{tabular}{|c|c|c|}
\hline Instrucción & Inicial & Final \\
\hline $\begin{array}{l}\text { Hoy desayune después de leer el } \\
\text { periódico; ¿Qué hice primero? }\end{array}$ & \multirow{3}{*}{$\begin{array}{l}\text { Contesta que no sabe en las dos } \\
\text { primeras. La última ya no se } \\
\text { aplicó. }\end{array}$} & $\sqrt{ }$ \\
\hline $\begin{array}{l}\text { A Pedro lo golpeó Juan; ¿Quién } \\
\text { le pegó a quién? }\end{array}$ & & $\begin{array}{c}\sqrt{ } \\
\text { (con apoyo en dibujo) }\end{array}$ \\
\hline $\begin{array}{l}\text { María es más alta que Ana pero } \\
\text { más baja que Lupe. }\end{array}$ & & $\begin{array}{c}\sqrt{ } \\
\text { (con apoyo en dibujo) }\end{array}$ \\
\hline
\end{tabular}

Tabla 11

Realización inicial y final de la tarea de señalar el cuadro que corresponde a la oración presentada verbalmente

\begin{tabular}{|l|l|l|}
\cline { 2 - 3 } \multicolumn{1}{c|}{} & Inicial & Final \\
\hline La caja está frente al barril & $\sqrt{ }$ & $\sqrt{ }$ \\
\hline El barril está bajo la caja & $\mathrm{X}$ & $\sqrt{ }$ \\
\hline La caja está dentro del barril & $\mathrm{X}$ & $\sqrt{ }$ \\
\hline El barril está sobre la caja & $\sqrt{ }$ & $\sqrt{ }$ \\
\hline El barril esta frente a la caja & $\mathrm{X}$ & $\sqrt{ }$ \\
\hline
\end{tabular}

En la escritura de J.E. era posible observar algunos errores de sustitución de letras (por ejemplo, l por r) y dificultades ortográficas. Además de que su escritura era lenta y seguía la estrategia fonológica (letra por letra). En la revaloración ya no se presentaran errores por sustitución de letras, pero se mantuvo sus dificultades ortográficas (que según el propio J.E. ya existían antes de su accidente). El proceso de escritura ya es automatizado (aunque se fija en algunas letras en función de sus dificultades ortográficas).

En la primera evaluación, la lectura era lentificada y se realizada fonológicamente (letra por letra) y con cambio de sonidos en algunas letras. En la revaloración la lectura es más fluida (aunque lenta, sin presencia de la estrategia fonológica). En ocasiones se observa cambio de sonidos, pero el paciente mismo se da cuento y corrige su lectura.

En el cálculo, en la primera evaluación, existió la dificultad en llevar a cabo la resolución de problemas, ya que el paciente se olvida de la pregunta a la que debe contestar (inicia las operaciones necesarias para la resolución, pero se olvida cual debe ser el próximo paso, siendo necesario el regreso al enunciado de la cuestión que, aún así, ni siempre es efectivo). En la revaloración J.E. logra realizar todos los pasos necesarios para la resolución del problema. Cuando este se dificulta, él presenta mayor dificultad pero con la orientación verbal él logra realizarlo.

Cabe mencionar acerca de las particularidades del lenguaje expresivo del paciente. Su lenguaje oral presentaba, en ocasiones, una inadecuada producción de los sonidos de las letras. En su habla había presencia esporádica de sustituciones cercanas por punto y modo de articulación (ej: foco por poco, aretes por adetes), pero estos errores no eran sistemáticos y con la repetición de la palabra el error no se presentaba en la mayoría de los casos. Por esta razón, se consideró inicialmente que estas dificultades podrían ser relacionadas 
con la debilidad en análisis y síntesis cinestesica como consecuencia secundaria de la afectación de zonas más profundas del lóbulo parietal y las conexiones con esta área (de acuerdo a lo que se presenta en su tomografía). Lo anterior, probablemente constituyó la causa de la presencia de su hemiparesia derecha. Actualmente en el lenguaje expresivo ya no se observan estos cambios.

\section{Discusión}

El diagnóstico diferencial es muy importante para un adecuado proceso de rehabilitación. Una mayor posibilidad de recuperación del enfermo implica en un diagnóstico adecuado del síndrome presentado por el paciente y por la apropiada descripción tanto de los síntomas primarios como las afectaciones secundarias. Es decir, el diagnóstico adecuado implica la detección del factor primario afectado y sus consecuencias secundarias. En este caso, siguiéndose la propuesta de Luria que sostiene que el síndrome está integrado no simplemente por síntomas aislados de múltiples dificultades en diversas pruebas, sino por un conjunto de síntomas, los cuales constituyen el efecto sistémico del factor afectado. De esta manera, se obtiene el cuadro clínico que incluye alteraciones del lenguaje expresivo e impresivo, de la lectura y de la escritura, de la memoria, de la actividad intelectual, etc. Considerar el síndrome afásico a partir de esta perspectiva significa no considerarlo únicamente como la alteración del lenguaje, sino incluyendo las alteraciones de los demás procesos psicológicos.

En este caso no es necesario rehabilitar estos procesos por separado. El programa de rehabilitación debe ser fiel al entendimiento del síndrome, siendo importante la construcción de un programa individualizado y completamente integrado con los resultados de la evaluación. Además, la rehabilitación neuropsicológica se debe apoyar en el principio de la formación gradual del eslabón (factor neuropsicológico) afectado, con el apoyo de los eslabones conservados.

Dentro de esta aproximación, la evaluación y la rehabilitación constituyen un proceso dinámico inseparable. La evaluación se basa en el análisis cualitativo, el cual permite la identificación de los factores alterados y conservados del paciente. De acuerdo a la evaluación cualitativa luriana, es necesario administrar diferentes tipos de tareas a los pacientes y analizar cómo se manifiestan las dificultades particulares en la realización de cada una de ellas. La observación más importante, cuando un clínico está evaluando a un paciente, se refiere a la naturaleza de las deviaciones o errores y cómo estos pueden ser explicados. Esto implica que el criterio de lograr o fallar de la evaluación cuantitativa estandarizada es insuficiente o, en lo mejor de los casos, es una aproximación gruesa inicial a las características del déficit. El análisis cualitativo de los errores será particularmente informativo considerando el déficit que se localiza en la base del problema. En la concepción luriana la información más importante es la naturaleza específica de las inhabilidades del paciente y la especificación del nivel en el cual el sistema funcional fue interrumpido (Ardila, 1999). Para ello lo esencial es observar la forma como el paciente realiza las tareas propuestas. Además, realizar modificaciones y ofrecerle ayudas produce datos importantes para el diagnóstico diferencial y para la rehabilitación, pues informa sobre las formas como el paciente puede superar sus dificultades. Así, durante el proceso de evaluación se descubren las vías para la rehabilitación.

Otro aspecto importante para el proceso de la rehabilitación es que este pueda incluir temas y actividades de interés del paciente para con eso lograr su motivación y envolvimiento, participando de forma activa en el proceso de trabajo. Nuestro paciente se presentaba a las sesiones con buena disposición y los trabajos que incluían el uso del dibujo lo motivaban más. El paciente también se incluía en el trabajo identificando en las sesiones las dificultades que se habían presentado y listando cuales eran las cosas que más le dificultaban en la ejecución de una u otra tarea.

Cabe hacer la consideración, a respecto de las habilidades de lectoescritura y calculo, de que se ven afectadas en los casos de afasia, como el hecho de que específicamente en este tipo de afasia (acústico-mnésica) estos procesos están relativamente conservados, el caso J.E. nos muestra exactamente esta situación.

En relación a las habilidades de lectura, escritura y calculo, aunque en J.E. estuvieran relativamente conservadas, hubo un prejuicio (principalmente en la ausencia de automatización del proceso) que, después de la rehabilitación alcanzó mejorías y ya se presenta automatizado.

De esta forma, en el caso presentado en este trabajo fue posible verificar en la revaloración la mejoría en el funcionamiento del factor primariamente afectado, como también de los factores afligidos secundariamente. De esta forma, el síndrome, por completo, fue incluido al trabajo. De esto, entonces, resultaron cambios positivos en la vida social (frecuenta fiestas) y laboral (retoma trabajo en su tienda de Internet). Además de que expresa deseos en retomar su vida, de regresar à sus estudios en la licenciatura. Eso demuestra la reorganización general de toda la esfera psíquica del sujeto.

\section{Conclusiones}

1. La relación sólida y constante entre el proceso de evaluación, diagnóstico y rehabilitación, deben estar siempre presentes en el proceso clínico con estos pacientes.

2. Las alteraciones del lenguaje no constituyen cuadros aislados, sino que forman parte de un síndrome que implica la afectación sistémica de otros procesos psicológicos.

3. El análisis de este caso permite establecer, dentro del cuadro sindrómico, el mecanismo neuropsicológico subyacente y de qué forma este mecanismo compromete las distintas actividades del sujeto.

4. Los resultados de la revaloración juntamente con descripciones de la vida actual del paciente, confirman los cambios en toda la esfera psíquica del enfermo al final del programa de rehabilitación.

5. El presente caso confirma la hipótesis de que en la afasia acústico-mnésica pura las imágenes internas no están alteradas.

6. El programa de rehabilitación fue eficaz en la recuperación de las funciones de lenguaje, lectura, escritura y cálculo. Al final el paciente se mostró capaz de empezar, aún de forma lenta y supervisada, sus actividades estudiantiles en la facultad de informática.

\section{Referencia Bibliográfica}

Ardila, A. (1999). Spanish applications of Luria's Assessment Methods. Neuropsychology Review, 9(2), 6370. 
Ardila, A. (2006). Las Afasias. Miami: Florida International University.

Ardila, A., \& Ostrosky-Solís, F. (2007). Diagnóstico del daño cerebral - enfoque neuropsicológico. México: Trillas.

Flores, J.C., Ostrosky-Solís, F., \& Lozano, A. (2008). Batería de Funciones Frontales y Ejecutivas: Presentación. Revista de Neuropsicología, Neuropsiquiatría y Neurociencias, 8(1), 141-158.

Guzmán, F. (2008). Fisiopatología del trauma craneoencefálico. Colombia Médica, 39(3),78-84.

Luria, A.R. (1947). Afasia traumática. Moscú: Academia de Ciencias Médicas de URSS.

Luria, A. R. (1978). Cerebro y lenguaje. Barcelona: Fontanella.

Luria, A.R., \& Tsvetkova, L.S. (1981). La resolución de problemas y sus trastornos. Barcelona: Fontanella.

Martínez, E. H. (1998). Traumatismos craneales: Fundamentos de patología, fisiopatología, clínica, diagnóstico y tratamiento. México: Ed. Universidad Autónoma de Puebla.

Quintanar, L. (1999). Modelos neuropsicológicos en afasiología. México: Ed. Universidad Autónoma de Puebla.

Quintanar, L., Solovieva, Y., \& León-Carrión, J. (2002). Diagnóstico de la afasia motora eferente: Estudio de un caso. Revista Española de neuropsicología, 4(4), 301-311.

Quintanar, L., \& Solovieva, Y. (2002). Análisis neuropsicológico de las alteraciones del lenguaje. Revista de Psicología General y Aplicada, 55(1), 67-87.

Quintanar, L., \& Solovieva, Y. (2003). Pruebas de evaluación infantil. México: Ed. Universidad Autónoma de Puebla.

Quintanar, L., \& Solovieva, Y. (2009). Evaluación neuropsicológica breve para adulto. México: Ed. Universidad Autónoma de Puebla.

Quintanar L., Solovieva Y., \& León-Carrión J. (2011). Diagnóstico clínico de la afasia Puebla-Sevilla. México-España (en prensa).

Solovieva, Y., \& Quintanar, L. (2005). Acerca de los mecanismos de la afasia acústico-mnésica: Estudio de caso. Revista Española de Neuropsicologia. 7(1), 17-34.

Tsvetkova, L.S. (1985). Rehabilitación neuropsicológica de los enfermos: Lenguaje y actividad intelectual. Moscú: Ed. Universidad Estatal de Moscú.

Tsvetkova, L.S. (1988). Afasia y enseñanza rehabilitatória. Moscú: Ed. Enseñanza.

Tsvetkova, L.S. (1996). Cerebro e intelecto. México: Ed. Universidad Autónoma de Morelos. 